\title{
PREVALENCE AND PREDICTORS OF SMOKING, QUIT ATTEMPTS AND TOTAL SMOKING BAN AT THE UNIVERSITY OF TURKU, FINLAND
}

\author{
Walid El Ansari ${ }^{1,2,3}$, Abdul Salam ${ }^{4}$ \\ 'Department of Surgery, Hamad General Hospital, Doha, Qatar \\ ${ }^{2}$ College of Medicine, Qatar University, Doha, Qatar \\ ${ }^{3}$ School of Health and Education, University of Skövde, Skövde, Sweden \\ ${ }^{4}$ Department of Epidemiology and Biostatistics, King Fahad Specialist Hospital, Dammam, Saudi Arabia
}

\section{SUMMARY}

Objectives: The current study employed socio-demographic, health and lifestyle, and academic variables to assess the prevalence and independent predictors of daily smoking, attempts to quit smoking, and agreement with total smoking ban at university.

Methods: Students at the University of Turku $(1,177)$ completed an online questionnaire that assessed socio-demographic, health and lifestyle, and academic characteristics, and three smoking variables (smoking, attempts to quit, agreement with total smoking ban at university). Bivariate relationships and multiple logistic regression assessed relationships between student characteristics and the three smoking variables before and after controlling for all other variables.

Results: Slightly $<80 \%$ of students never smoked, $16 \%$ were occasional, and about $6 \%$ were daily smokers, and about $40 \%$ had attempted to quit. Nearly half the sample agreed to total smoking ban at university. Physical activity, consuming alcohol, illicit drug/s use and daily smoking were significant independent predictors across $>1$ of the three smoking variables. Age, health awareness, importance of achieving good grades, academic performance compared to peers, study burden, and mother's educational level were significant independent predictors of one of the three variables examined.

Conclusion: Universities need to assess smoking, with specific focus on the modifiable independent predictors that were associated with $>1$ the variables examined, to encourage physical activity and pay attention to reduce alcohol consumption and illicit drug/s and daily smoking, whilst targeting at-risk students. University strategies should be part of the wider country-wide effective tobacco control policies.

Key words: quitting, smoking ban, Finland, university students

Address for correspondence: W. El Ansari, Department of Surgery, Hamad General Hospital, Doha 3050, Qatar. E-mail: welansari9@gmail.com https://doi.org/10.21101/cejph.a6576

\section{INTRODUCTION}

Tobacco smoking among university students remains a substantial issue globally. The transition from high school to university can be a demanding period (1), and smoking is common on university campuses (2). The rates of smoking among students amount to $1 / 3$ of the college student population (3), e.g. $16.7 \%$ daily smokers and $11 \%$ smoking $>10$ cigarettes/day (Denmark and Sweden, respectively) $(4,5) ; 10 \%$ men and $9.6 \%$ women daily smokers (Norway) (6); 32.89\% current smokers $(51 \%$ $<22$ years old) (Italy) (7); and $15.8 \%$ daily and $12 \%$ occasional smokers (United Kingdom, mean age 25 years) (8). Tobacco is a preventable factor of ill health, where choices that young adults make influence life expectancy across their life course.

Given the alarming rates of tobacco smoking among young adult populations, tobacco control strategies are being implemented by universities $(2,7)$, and are associated with reduced prevalence of smoking $(9,10)$. Smoke-free policies diminish the social acceptability of tobacco use, and smoking prevalence and uptake (11), and have been endorsed by students $(2,8,9,12)$.
Socio-demographic, academic, and health and lifestyle variables are important when examining tobacco smoking among university students. Hence, the current study included gender and age $(2,8)$, accommodation/living arrangements (13), religiosity (14), depressive symptoms (8), physical activity (15), psychological and academic stress $(8,16)$, health awareness $(7)$, alcohol consumption (17), academic achievement (18), and study burdens (8). Controlling for such variables is important to assess the correlates of smoking and their links with student characteristics.

The literature suggests knowledge gaps. Whilst few recent studies exist on e.g. alcohol and illicit drug/s use $(19,20)$ of university students in Finland, there is no recent research on the predictors of tobacco smoking, except for a few outdated studies (21). Research has focused on smoking among younger students and adolescents $(13,18)$, despite the Tobacco Act that aims to reduce tobacco consumption in Finland by 2030 (22), to make Finland smoke-free by 2040 (23). The current study addresses these gaps. It surveyed undergraduates across 7 faculties at a university in Finland. We employed socio-demographic, health and lifestyle, and academic variables to describe the prevalence 
of smoking, attempts to quit smoking, and agreement with smoking ban.

\section{MATERIALS AND METHODS}

The current study compared the bivariate relationships of the socio-demographic, health and lifestyle, and academic variables with the different aspects of smoking as dependent variables; and assessed the independent predictors associated with smoking. We describe the prevalence of smoking, attempts to quit smoking and attitudes towards smoking ban, and assess the variables independently associated with daily smoking, quit attempts, and agreement with total smoking ban at university.

\section{Ethics, Sample, and Data Collection}

The Research and Ethics Committee at the University approved the study (\# Lausunto 10/2010). Initial invitation emails to partake in the online English survey were dispatched to all undergraduates at all faculties, University in Turku, Finland during the academic year 2013-2014. The study is detailed elsewhere (19). The total number of students invited was 4,387; 1,177 completed questionnaires were received. Average age of participants was $\approx 23$ (SD 5 ) years; females comprised $70.4 \%$. Response rate was $\approx 27 \%$. The University of Turku is the third largest university in Finland, comprising 7 faculties (Education, Humanities, Law, Medicine, Science and Engineering, Social Sciences, and Economics). It is a smoke-free work and study place where smoking is permitted only in designated areas.

\section{Health and Wellbeing Questionnaire}

The Health and Wellbeing Questionnaire was used. This tool was utilized among college students in many countries $(2,8$, 24-33). The questionnaire comprised socio-demographic, health, mental wellbeing, academic, and health behaviour/lifestyle characteristics. The questionnaire also collected information about religiosity, and students' perceptions of the burden of university study.

\section{Socio-demographic Variables}

Age, sex and year of study at university were based on selfreports. Age was used as a continuous variable.

Marital status: "What is your marital status?" Response options included single, married, or other (please specify), dichotomized into 'single' vs. 'married or in relationship' $(24,26)$.

Accommodation (living arrangements) during semester: "Where do you live during university/college term time?", dichotomized into 'living with parents' vs. 'not living with parents' (24).

Religiosity (personal importance of religious faith): the extent to which participants agreed/disagreed with the statement: "My religion is very important for my life", 1 = 'strongly agree', 2 = 'somewhat agree', 3 = 'neither agree nor disagree', $4=$ ='somewhat disagree', and $5=$ 'strongly disagree', recoded into 2 categories based on agreement/disagreement $(1,2,3=1$ vs. $4,5=2)(24,26)$.

Parental education (socioeconomic status, 2 items): "What is the highest education level of your father?" The same question was asked about mother's education level (no formal education, primary school, secondary school, high school, bachelor's degree, master's degree, and Ph.D. or equivalent). For the current analysis, we employed the highest education (at least bachelor's) of either parent (20).

Income sufficiency: "How sufficient do you consider your income?" with four Likert scale responses ('always sufficient', 'mostly sufficient', 'mostly insufficient' or 'insufficient') which were then dichotomized into 'always sufficient' vs. 'other' (19).

Discipline of study: students were asked about the faculty they were enrolled at, and discipline they were studying. For the analysis we collapsed the seven faculties into five.

\section{Educational Variables}

The current study assessed academic performance using 2 items:

Students' internal reflection on their academic performance (importance attached to achieving good grades): "How important is it for you to have good grades at university?" (4 response categories, $1=$ 'very important', 2 = 'somewhat important', 3 = 'not very important', and $4=$ 'not at all important'), dichotomized into $1=$ 'somewhat important or very important' vs. 2 = 'other' $(19,28)$.

Students' subjective comparative appraisal of their performance in comparison with their peers: "How do you rate your performance in comparison with your fellow students?" 1 = 'much better', 2 = 'better', 3 = 'same', 4 = 'worse', 5 = 'much worse', dichotomized based on perceived better performance $(4,5=1 \mathrm{vs} .1,2,3=2)$ (19).

Burdens of university study ( 1 item): this appraised the burdens associated with university study. Students responded to the question "To what extent do you feel burdened in the following areas: studies in general?" (6-point Likert scale: $1=$ 'not at all' $-6=$ 'very much'), later dichotomized into $(4,5=$ yes vs. $1,2,3=$ no) $(8)$.

\section{Health Variables}

Self-rated general health: "How would you describe your general health?" ( 1 = 'poor', 5 = 'excellent') adopted from (34).

Health awareness: "To what extent do you keep an eye on your health?" (1 = 'not at all', 4 = 'very much') (19).

Depressive symptoms (20 items): using the Modified Beck Depression Inventory (M-BDI) $(35,36)$. Sample items included: "I feel sad," "I feel I am being punished," "I have thoughts of killing myself," "I have lost interest in other people," "I have to force myself to do anything". BDI computes a single score for individual respondents by summing their responses for all items of the scale. We used the 4th quintile to categorize depressive symptoms as high.

Perceived Stress Scale (4 Items): Cohen's Perceived Stress Scale (PSS) in its four-item short form (37) assessed the extent to which participants considered life situations to be stressful. PSS-4 measures the degree to which situations in one's life over the past month are appraised as stressful. The questions detect how unpredictable, uncontrollable, and overloaded respondents find their lives. All items began with: "In the past month, how often have you felt...?" (5-point scale: 1 = 'never', 2 = 'almost never', 3 = 'sometimes', 4 = 'fairly often', 5 = 'very often'). In our sample, Cronbach's alpha of PSS was 0.75. A perceived stress score was generated by summing the responses to the 4 
questions. A median split (median $=14)$ categorized the variable into 'higher $\geq$ median' and 'lower $<$ median' stress (higher scores $=$ more perceived stress) (20).

\section{Lifestyle Variables}

Smoking (2 items) and attempt/s to quit smoking (1 item): students were asked "Within the last three months, how often did you smoke (cigarettes, pipe, cigarillos, cigars)?" (three response scales: 'daily', 'occasionally', 'never'). For smokers, the number of cigarettes smoked: "How many cigarettes do you smoke on average?". Attempt/s to quit smoking were measured by asking smokers: "Have you tried to quit smoking within the last 12 months?" (two response scales: yes, no) (38).

Agreement with total smoking ban (1 item): students were asked about the extent of their disagreement/ agreement with the statement "There should be no smoking on the university premises at all' (five-point scale: 'strongly disagree', 'disagree', 'neutral', 'agree', 'strongly agree') (8).

Frequency of alcohol consumption (1 item): "Over the past 3 months how often did you drink alcohol, for example, beer?" (6 response options: 'never', 'once a week or less', 'once a week', 'a few times each week', 'every day', and 'a few times each day'), later dichotomised into no $=$ 'never' vs. yes $=$ 'once a week or less', or 'once a week', or 'a few times each week', or 'every day', or 'a few times each day' (19).

Illicit drug/s use: "Have you ever use/used drugs?” ('yes, regularly', 'yes, but only a few times', 'never'), later dichotomised into yes $=$ 'regularly or only a few times' vs. no = 'never' $(20$, $24,26,34)$.

Low physical activity (PA) (1 item): defined as achieving 0 vigorous and 0 or 1 day of moderate exercise in the past 7 days $(27,39)$. This was computed from two types (levels) of PA that were measured. Moderate exercise (1 item): "On how many of the past 7 days did you participate in moderate exercise for at least 30 minutes?" ratings ranged from 0 to 7 days (40). Vigorous exercise (1 item): "On how many of the past 7 days did you participate in vigorous exercise for at least 20 minutes?" (ratings ranged from 0 to 7 days (40).

Number of servings of fruits/vegetables consumed per day: "How many servings of fruits and vegetables do you usually have per day ( 1 serving $=1$ medium piece of fruit, 1/2 cup chopped, cooked, or canned fruits/vegetables, $3 / 4$ cup fruit/vegetable juice, small bowl of salad greens, or $1 / 2$ cup dried fruit)?" The response scales were: 'I don't eat fruits and vegetables', '1-2 times', '3-4 times', or ' 5 or more times' $(8,29)$.

\section{Statistical Analysis}

Descriptive and inferential statistics characterized the study sample and tested hypotheses. Quantitative variables are presented as mean \pm standard deviation, while numbers (percentage) were used for qualitative variables. Bivariate analysis (independent sample t-test, Pearson's chi-square or Fisher's exact test as appropriate) assessed the relationship between socio-demographic data, health and mental wellbeing variables, academic characteristics, burdens of university study, income sufficiency, religiosity, health behaviour/lifestyle data, smoking, attempts to quit smoking, and perceptions towards total smoking ban on campus.
Multiple binary logistic regression models identified the significant independent predictors of daily smoking, attempts to quit smoking, and attitudes towards smoking ban at university. Some continuous variables were dichotomized (e.g., BDI score, perceived stress, number of cigarettes smoked) to better interpret the findings. Odds ratio (OR) was reported, and adjusted odds ratio (AOR) for each of the three dependent variables (daily smoking, attempts to quit smoking, and attitudes towards smoking ban on university premises) adjusted for potential confounders (sex, age, study discipline, accommodation, marital status, religiosity, parental education, burdens of university study, income sufficiency, selfrated health, health awareness, depressive symptoms, perceived stress, alcohol consumption, illicit drug/s use, PA, importance of achieving good grades, an academic performance compared to one's peers). Wald test computed on each factor determined which were significant. AOR and $95 \%$ confidence interval for the AOR were reported. Statistical significance was set at $\mathrm{p}<0.05$ (two-tailed). Hosmer-Lemeshow assessed the model's goodnessof-fit. Statistical Package for Social Sciences Version 24 (SPSS) was used.

\section{RESULTS}

\section{Socio-demographic, Lifestyle and Educational Char- acteristics of the Sample}

About $70 \%$ of the sample were females, mean age was about 23 years and roughly half were first year students (Table 1). Two disciplines (Technology \& Science and Humanities) each contributed about $28 \%$ of the sample. About half the sample were singles, two thirds were not living with parents, and $36.1 \%$ had both parents with high educational level (at least bachelor's degree). Most students had high health awareness, self-rated their health favourably, did not report financial burden/s, and more than half felt that university study was a burden. About three quarters of the sample did not report depressive symptoms, although nearly $60 \%$ perceived high stress. Most students were physically active, but most did not eat $\geq 5$ portions of fruit or vegetable daily. Whilst $90 \%$ of students drank alcohol, about one fifth had any lifetime use of illicit drug/s. Most respondents rated their academic performance compared to peers and the importance of achieving good grades favourably.

\section{Prevalence of Smoking, Attempts to Quit Smoking and Attitudes towards Total Smoking Ban: Whole Sample}

Slightly $<80 \%$ of the sample had never smoked, $16 \%$ were occasional smokers, about $6 \%$ were daily smokers (Table 1 ). Smokers smoked an average of 8 cigarettes/day. Among smokers, about $40 \%$ had attempted to quit. Nearly half the sample agreed that there should be no smoking on university premises at all, about one fifth disagreed and about one third were neutral.

\section{Prevalence of Smoking, Attempts to Quit Smoking and Attitudes towards Total Smoking Ban by Discipline}

There were no differences across the five disciplines in terms of daily, occasional or never smokers, the number of cigarettes 
Table 1. Descriptive characteristics of undergraduates at University of Turku, Finland $(N=1,177)$

\begin{tabular}{|c|c|}
\hline Variable & $\begin{array}{l}\text { Value } \\
\mathrm{n}(\%)\end{array}$ \\
\hline Age (years) ${ }^{\mathrm{a}}$ & $22.96(5.21)$ \\
\hline \multicolumn{2}{|l|}{ Gender } \\
\hline Male & $346(29.6)$ \\
\hline Female & $823(70.4)$ \\
\hline \multicolumn{2}{|l|}{ Year of study } \\
\hline $1 s t$ & $553(47.2)$ \\
\hline 2nd & $344(29.4)$ \\
\hline $3 r d$ & $251(21.4)$ \\
\hline$\geq 4$ th & $23(2.0)$ \\
\hline \multicolumn{2}{|l|}{ Discipline of study at University } \\
\hline Education and Law & $188(16.4)$ \\
\hline Economics & $138(12)$ \\
\hline Medicine & $168(14.6)$ \\
\hline Technology \& Science & $328(28.5)$ \\
\hline Humanities & $327(28.5)$ \\
\hline \multicolumn{2}{|l|}{ Marital status } \\
\hline Married or in relationship & $593(50.7)$ \\
\hline Single & $576(49.3)$ \\
\hline \multicolumn{2}{|l|}{ Accommodation during semester } \\
\hline With parents & $394(33.7)$ \\
\hline Not with parents & $776(66.3)$ \\
\hline \multicolumn{2}{|l|}{ Parental educational level } \\
\hline Both parents low & $137(19.8)$ \\
\hline Mother low, father high & $133(19.2)$ \\
\hline Mother high, father low & $174(25.1)$ \\
\hline Both parents high & $249(35.9)$ \\
\hline \multicolumn{2}{|l|}{ Health awareness } \\
\hline Not at all/not much & $159(13.6)$ \\
\hline To some extent/very much & $1,009(86.4)$ \\
\hline \multicolumn{2}{|l|}{ Self-rated general health } \\
\hline Poorlfair & $87(7.4)$ \\
\hline Good/very good/excellent & $1,083(92.6)$ \\
\hline \multicolumn{2}{|l|}{ Religiosity (importance of religion in life) } \\
\hline Strongly or somewhat agree/neither agree nor disagree & $464(39.8)$ \\
\hline Strongly disagree/somewhat disagree & $702(60.2)$ \\
\hline \multicolumn{2}{|l|}{ Income sufficiency } \\
\hline Always sufficient & $149(12.8)$ \\
\hline Mostly sufficient & $525(45.2)$ \\
\hline Mostly insufficient & $322(27.7)$ \\
\hline Always insufficient & $166(14.3)$ \\
\hline \multicolumn{2}{|l|}{ Study burden } \\
\hline No & $470(40.1)$ \\
\hline Yes & $703(59.9)$ \\
\hline BDI score ${ }^{a}$ & $50.88(18.4)$ \\
\hline
\end{tabular}

\section{Variable}

Value

$\mathrm{n}(\%)$

Depressive symptoms $\mathrm{a}^{\mathrm{a} b}$ (BDI cut-off at 4th quintile)

\begin{tabular}{|l|l|}
\hline No & \\
\hline Yes & 297 \\
\hline
\end{tabular}

$879(74.7)$

Perceived stress (cut-off at median)

\begin{tabular}{|l|l|}
\hline Low (< median) & $463(39.4)$ \\
\hline High ( $\geq$ median) & $713(60.6)$ \\
\hline
\end{tabular}

Smoking (last 3 months)

\begin{tabular}{|l|c|}
\hline Daily & $74(6.3)$ \\
\hline Occasionally & $183(15.7)$ \\
\hline Never & $911(78)$ \\
\hline How many cigarettes do you smoke daily on average? $?^{\mathrm{a}, \mathrm{c}}$ & $8.24(5.35)$ \\
\hline
\end{tabular}

Attempted to quit smoking (within last 12 months) ${ }^{d}$

\begin{tabular}{|l|c|}
\hline No & $147(61.3)$ \\
\hline Yes & $93(38.8)$ \\
\hline
\end{tabular}

There should be no smoking on university premises at all

\begin{tabular}{|l|l|}
\hline Strongly disagree/disagree & $232(19.8)$ \\
\hline Neutral & $366(31.5)$ \\
\hline Strongly agree/agree & $568(48.6)$ \\
\hline
\end{tabular}

Physical activity

\begin{tabular}{|l|l|}
\hline High & $958(81.4)$ \\
\hline Low & $219(18.6)$ \\
\hline
\end{tabular}

Eating $\geq 5$ portions of fruit or vegetable daily

\begin{tabular}{|l|c|}
\hline No & $1,029(87.8)$ \\
\hline Yes & $143(12.2)$ \\
\hline
\end{tabular}

Alcohol (in last 3 months before survey)

\begin{tabular}{|l|c|}
\hline Yes & $1,015(86.7)$ \\
\hline No & $156(13.3)$ \\
\hline
\end{tabular}

Lifetime illicit drug/s use

\begin{tabular}{|l|l|}
\hline No & $921(79)$ \\
\hline Yes & $245(21)$ \\
\hline
\end{tabular}

Academic performance compared to peers

\begin{tabular}{|c|c|}
\hline Same, better or much better & $992(84.6)$ \\
\hline Worse or much worse & $180(15.4)$ \\
\hline \multicolumn{2}{|l|}{ Importance of achieving good grades } \\
\hline Somewhat or very important & $971(83.1)$ \\
\hline Not important or at all important & $198(16.9)$ \\
\hline
\end{tabular}

Numbers in parenthesis represent column percentages unless indicated otherwise *two-sided p-values based on Pearson's chi square and Fisher's exact test (categorical variables), and t-test for comparison between means (continuous variables); ${ }^{a}$ mean (standard deviation); ${ }^{\circ} \mathrm{BDI}$ - Beck Depression Inventory, numbers might not sum up to total due to missing values; ' for daily smokers only; 'among daily or occasional smokers, $\mathrm{n}=257$.

smoked, the attempts to quit smoking, and the views on whether there should be a strict no smoking policy on university campus (Table 2). 
Table 2. Smoking related variables of undergraduates at University of Turku, Finland, by discipline $(N=1,177)$

\begin{tabular}{|c|c|c|c|c|c|c|c|}
\hline Variable & $\begin{array}{l}\text { Total } \\
\text { n (\%) }\end{array}$ & $\begin{array}{l}\text { Education and } \\
\text { Law } \\
(n=187) \\
n(\%)\end{array}$ & $\begin{array}{c}\text { Economics } \\
(n=135) \\
n(\%)\end{array}$ & $\begin{array}{c}\text { Medicine } \\
\text { (n= 168) } \\
n(\%)\end{array}$ & $\begin{array}{c}\text { Technology \& } \\
\text { Science } \\
(\mathrm{n}=324) \\
\mathrm{n}(\%)\end{array}$ & $\begin{array}{l}\text { Humanities } \\
(n=327) \\
n(\%)\end{array}$ & $\mathrm{p}$-value \\
\hline \multicolumn{8}{|l|}{ Smoking, last 3 months } \\
\hline Daily & $71(6.2)$ & $12(6.4)$ & $11(8)$ & $8(4.8)$ & $19(5.8)$ & $21(6.5)$ & \multirow{3}{*}{0.740} \\
\hline Occasional & $179(15.7)$ & $27(14.4)$ & $18(13.1)$ & $22(13.3)$ & $52(16)$ & $60(18.5)$ & \\
\hline Never & $890(78.1)$ & $148(79.1)$ & $108(78.8)$ & $136(81.9)$ & $255(78.2)$ & $243(75)$ & \\
\hline \multicolumn{8}{|c|}{ Number of cigarettes smoked per day } \\
\hline$<5$ & $18(27.7)$ & $3(27.3)$ & $3(30)$ & $1(12.5)$ & $7(43.8)$ & $4(20)$ & \multirow{3}{*}{0.621} \\
\hline 5 to $<10$ & $21(32.3)$ & $5(45.5)$ & $3(30)$ & $2(25)$ & $5(31.3)$ & $6(30)$ & \\
\hline$\geq 10$ & $26(40)$ & $3(27.3)$ & $4(40)$ & $5(62.5)$ & $4(25)$ & $10(50)$ & \\
\hline \multicolumn{8}{|c|}{ Attempt/s to quit smoking (smokers only, $n=257$ ) } \\
\hline No & $144(61.8)$ & $21(60)$ & $16(64)$ & $17(60.7)$ & $38(55.9)$ & $52(67.5)$ & \multirow{2}{*}{0.700} \\
\hline Yes & $89(38.2)$ & $14(40)$ & $9(36)$ & $11(39.3)$ & $30(44.1)$ & $25(32.5)$ & \\
\hline \multicolumn{8}{|c|}{ Total smoking ban on university premises } \\
\hline Strongly disagree/disagree & $226(19.7)$ & $40(21.3)$ & $23(16.7)$ & $29(17.4)$ & $55(16.9)$ & $79(24.2)$ & \multirow{3}{*}{0.268} \\
\hline Neutral & $361(31.5)$ & $58(30.9)$ & $49(35.5)$ & $52(31.1)$ & $113(34.7)$ & $89(27.2)$ & \\
\hline Strongly agree/agree & $559(48.8)$ & $90(47.9)$ & $66(47.8)$ & $86(51.5)$ & $158(48.5)$ & $159(48.6)$ & \\
\hline
\end{tabular}

Table 3. Association between attempts to quit smoking and support for total smoking bans on university premises by current smoking status: undergraduates at University of Turku, Finland $(N=1,177)$

\begin{tabular}{|c|c|c|c|c|c|}
\hline \multirow[b]{2}{*}{ Variable } & \multicolumn{4}{|c|}{ Smoking (last 3 months) } & \multirow[b]{2}{*}{$\mathrm{p}$-value } \\
\hline & $\begin{array}{c}\text { Total }(n=240) \\
n(\%)\end{array}$ & $\begin{array}{c}\text { Daily }(n=72) \\
n(\%)\end{array}$ & $\begin{array}{c}\text { Occasional }(n=168) \\
n(\%)\end{array}$ & $\begin{array}{l}\text { Never } \\
\text { NA }\end{array}$ & \\
\hline \multicolumn{6}{|c|}{ Attempt/s to quit smoking (smokers only, $n=256$ ) } \\
\hline No & $147(61.3)$ & $31(43.1)$ & $116(69)$ & NA & \multirow{2}{*}{$<0.001$} \\
\hline \multirow[t]{2}{*}{ Yes } & $93(38.8)$ & $41(56.9)$ & $52(31)$ & NA & \\
\hline & $\begin{array}{c}\text { Total }(n=1,165) \\
n(\%)\end{array}$ & $\begin{array}{c}\text { Daily }(n=74) \\
n(\%)\end{array}$ & $\begin{array}{c}\text { Occasional }(n=183) \\
n(\%)\end{array}$ & $\begin{array}{c}\text { Never }(n=908) \\
n(\%)\end{array}$ & \\
\hline \multicolumn{6}{|c|}{ Total smoking ban on university premises } \\
\hline Strongly disagree/disagree & $232(19.9)$ & $51(68.9)$ & $71(38.8)$ & $110(12.1)$ & \multirow{3}{*}{$<0.001$} \\
\hline Neutral & $368(31.6)$ & $19(25.7)$ & $64(35.0)$ & $285(31.4)$ & \\
\hline Strongly agree/agree & $565(48.5)$ & $4(5.4)$ & $48(26.2)$ & $513(56.5)$ & \\
\hline
\end{tabular}

NA - not applicable

Attempts to Quit Smoking and Attitudes towards Total Smoking Ban by Current Smoking Status

Table 3 shows that there were significant differences between daily and occasional smokers in terms of attempts to quit smoking, where daily smokers had significantly more attempts at quitting than occasional smokers. Likewise, significantly more proportions of daily smokers strongly disagreed/disagreed on the total smoking ban on campus than occasional smokers or never smokers.

\section{Independent Predictors of Daily Smoking, Attempt/s to Quit Smoking, and Total Smoking Ban at Univer- sity}

Table 4 shows the results of the bivariate analysis (OR) and the multiple logistic regression (independent predictors, AOR).
For daily smoking, older age and low PA were significant independent positive predictors of daily smoking. Conversely, higher health awareness, no alcohol consumption during last 3 months and never lifetime illicit drug/s use were significant independent negative predictors of daily smoking. All other variables were non-significant.

As for attempts to quit smoking, daily smoking and rating one's academic performance compared to peers as 'worse or much worse' were significant independent positive predictors of quit attempts. Conversely, low PA and rating the importance of achieving good grades at university as not important/not at all important were each a significant independent negative predictor of quit attempts. All other variables were non-significant.

In terms of agreement with total smoking ban, no consumption of alcohol during the last 3 months, never lifetime illicit drug/s 


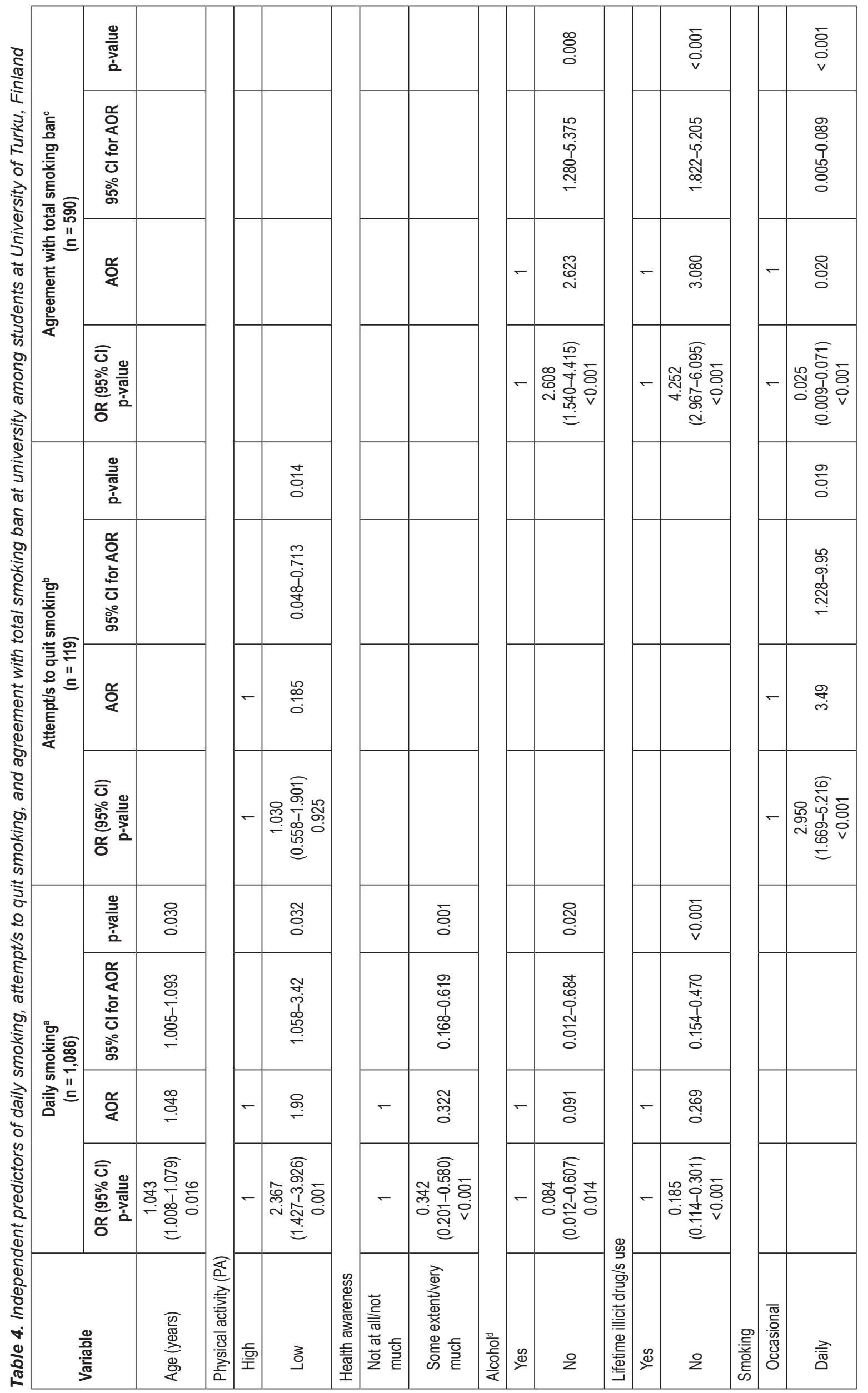




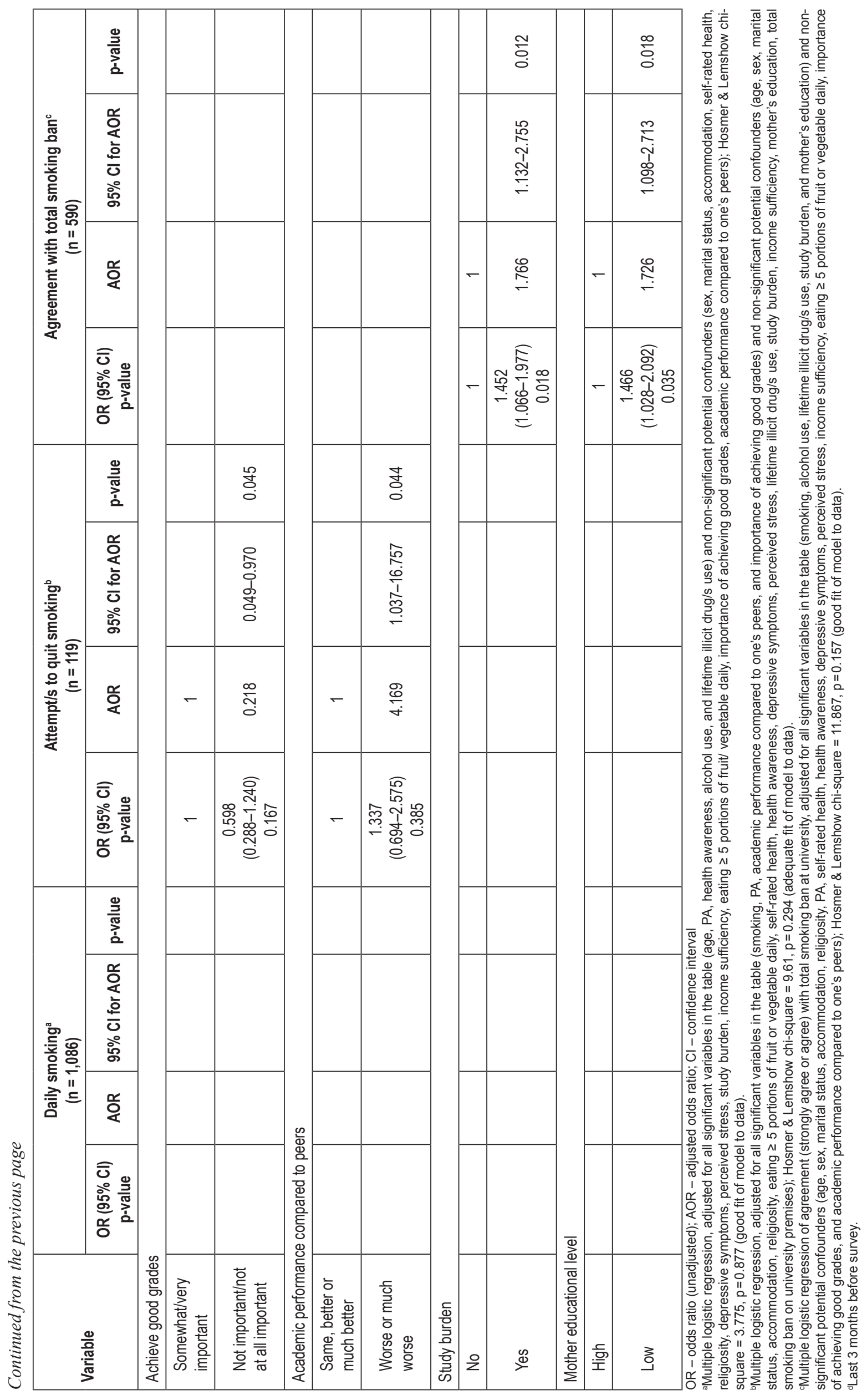


use, feeling high study burden, and low mother's education were significant independent positive predictors of agreement with university smoking ban. Conversely, daily smoking was a significant independent negative predictor of agreement with smoking ban. All other variables were non-significant.

\section{Independent Predictors across the Three Variables Examined}

Table 5 shows the summary of independent predictors of daily smoking, attempts to quit smoking, and agreement with total smoking ban at university. After adjustment for all student characteristics, some factors were independent predictors across more than one of the variables. Students reporting low PA were more likely to be daily smokers and less likely to have attempted to quit smoking. Likewise, those not consuming alcohol were less likely to be daily smokers and more likely to agree with a total smoking ban at university. Similarly, those with never lifetime illicit drug/s use were less likely to be daily smokers and were much more likely to agree with a total smoking ban at university. Conversely, although daily smokers were more likely to have attempted to quit smoking, they were less likely to agree with a total smoking ban at university.

\section{DISCUSSION}

Young adult smokers exhibit the highest smoking rates, and university smokers are a high percentage of this population (41). The present study provides evidence that lifestyles of students are a concerning public health issue that could contribute to noncommunicable diseases among this young adult population. The study described the prevalence of smoking, attempts to quit smoking and attitudes towards total smoking ban, and assessed the socio-demographic, health, lifestyle, and academic characteristics independently associated with these three variables. To the best of our knowledge, this study is the first to conduct such an undertaking among undergraduates in Finland.
In terms of prevalence, slightly $<80 \%$ of the sample had never smoked, $16 \%$ were occasional smokers, about $6 \%$ were daily smokers, and there were no gender differences in terms of smoker status. Across a UK sample of students, and employing the same tools as the current study, $72.2 \%$ of the sample never smoked, $12 \%$ reported occasional smoking, while $15.8 \%$ were daily smokers (during the last three months), and there were gender differences in terms of smoker status (8). Hence, compared to the UK (8), the current sample of Finns exhibited more occasional but less daily smokers. Elsewhere, $7.2 \%$ of medical students had ever smoked and $0.7 \%$ were current smokers (42). Whilst differences between studies may be due to the different reasons why people smoke (43), however, it is also not clear whether reported findings refer to daily or occasional smokers. Research would benefit from a standardized reporting of smoking behaviour to assist better comparisons of findings across studies. Nevertheless, the levels observed among this current sample remain a concern, particularly that cigarette smoking is viewed as 'an entry point' to illicit drug use. In 2019, 11\% of the Finnish adult population over the age of 20 years smoked daily, and $18.5 \%$ of young people attending vocational institutes smoked (44).

As regards to attempts to quit smoking, among these Finnish smokers, about $40 \%$ had attempted to quit within the last 12 months prior to the survey (no gender difference). This quit attempt level is lower than that seen in the UK (used the same questionnaire employed in the current study), where among students about every second smoker (55\%) had attempted to quit (8); and was also considerably lower than that reported among smoker students in Egypt (used the same questionnaire employed in the current study), where about $76 \%$ of smokers had attempted quitting within the last year before the survey (2). Others reported a $64.9 \%$ past year quit attempt rate among male students signed up in a smoking cessation service (41). One speculation could be that our lower quit attempt rates could be due to a longer smoking period, or smoking a greater number of cigarettes, as higher amounts of cigarette smoking have stronger nicotine dependence (41). An interesting finding is that mean quit attempts were higher among daily than occasional smokers (56.9\% vs. $31 \%)$,

Table 5. Summary: independent predictors of daily smoking, quit attempts, and agreement with total smoking ban at university among students of University of Turku, Finland

\begin{tabular}{|c|c|c|c|}
\hline Variable & Daily smoking & $\begin{array}{l}\text { Attempt/s to quit } \\
\text { smoking }\end{array}$ & $\begin{array}{l}\text { Agreement with total } \\
\text { smoking ban }\end{array}$ \\
\hline Age & + & $\mathrm{N}$ & $\mathrm{N}$ \\
\hline Physical activity (low) & ++ & -- & $\mathrm{N}$ \\
\hline Health awareness (low) & -- & $\mathrm{N}$ & $\mathrm{N}$ \\
\hline Alcohol (last 3 months before survey) (no) & --- & $\mathrm{N}$ & +++ \\
\hline Lifetime illicit drug/s use (no) & -- & $\mathrm{N}$ & +++ \\
\hline Smoking (daily) & NA & +++ & --- \\
\hline Importance of achieving good grades (not important) & $\mathrm{N}$ & -- & $\mathrm{N}$ \\
\hline Academic performance compared to peers (worse or much worse) & $\mathrm{N}$ & +++ & $\mathrm{N}$ \\
\hline Study burden (yes) & $\mathrm{N}$ & $\mathrm{N}$ & ++ \\
\hline Mother's educational level (low) & $\mathrm{N}$ & $\mathrm{N}$ & ++ \\
\hline
\end{tabular}

+ positive predictor (risk factor); + + strong positive predictor; + + + stronger positive predictor; + + + + extremely strong positive predictor; - negative predictor (protective factor); - - strong negative predictor; - - - stronger negative predictor; NA - not applicable; $\mathrm{N}$ - no independent effect detected. 
perhaps reflecting the fact that occasional smokers might not view themselves as 'real' smokers and hence fell less pressure to quit.

As for physical activity (PA), our finding that PA is protective against smoking agrees with others (48). Others found that a cluster of unhealthy lifestyles/high risk students were characterized by high tobacco consumption and low PA, and conversely, another healthy lifestyles/low risk cluster exhibited high PA levels and low tobacco use (15). In Spain, 83.9\% of exercising college students were not current smokers (43), and current smokers were significantly more likely to be physically inactive than those who never smoked (49). Indeed, behavioural interventions that combine smoking cessation and PA may be more effective than either smoking cessation or PA alone (50).

As for alcohol consumption, our finding that alcohol is a significant risk factor for daily smoking agrees with others (51), and among university students, smokers were 2.72 times more likely to binge drink (52). As for lifetime illicit drug/s use, our finding that illicit drug/s use was a significant risk factor for daily smoking supports other research where drug use was significantly associated with daily smoking among students (2, 8). Among students, ever smoking was positively associated with ever drug use (53), and illicit substance use clustered with tobacco consumption (54).

The current study observed an important set of demographic, health and educational variables (age, mother's educational level, health awareness, importance of achieving good grades, academic performance compared to peers, study burden) that were significantly associated with one of the variables under examination. We found that age was independent predictor of daily smoking, in support of research among university students, where current cigarette smoking for the whole sample was significantly associated with age (55). Likewise, we observed that low mother's educational level was a strong positive independent predictor of agreement with total smoking ban at university, in support that students whose mothers completed at least a bachelor's degree had $\approx 3$ times more probability to smoke daily compared to those with mother's education less than bachelor degree (adjusted OR $=2.98,1.77-5.0)$ (2). Similarly, among the current Finns, not achieving good grades negatively predicted their attempts to quit smoking, in agreement that students' poor lifestyle choices could affect future academic performance (16).

This study has limitations and findings should be cautiously generalized. Self-reported data might suffer from recall bias and social desirability that could underestimate the prevalence of smoking. In cross-sectional studies relationships are associations and not causations. The findings are from one university, not to be extrapolated to the general university students in Finland. The response rate from various disciplines could have been different, and hence generalizations to all university students need to be cautious. Students were not randomly selected. Non-response could be due to smoker status, and students less/uninterested in healthy practices might be less motivated to participate and underrepresented. It would have been beneficial to compare the profiles of responders with non-responders to detect any differences, but data was not available. We observed no significant relationships between smoking behaviours and e.g., eating habits, religiosity, self-rated general health, perceived stress, and others possibly due to a real lack of association or due methodological matters, e.g., sample size and statistical power of the study. It would have been useful to examine other factors, e.g., family support, onset of smoking, peer pressure, social norms, self-efficacy, smoking motives, and internet addiction. Finally, the study did not follow the prevalence of ex-smokers, as some of the never smokers could have been ex-smokers with quit attempt/s in the last 12 months.

Despite these limitations, the study has important strengths. To the best of our knowledge, no previous study, particularly in Finland, assessed the prevalence and predictors independently associated with daily smoking, with attempts to quit smoking, and with agreement with total smoking ban on university premises across undergraduates from a variety of faculties. We employed a range of socio-demographic, health and lifestyle variables. Likewise, we included 2 academic outcomes to assess associations between smoking and two 'upstream' academic performance indicators (students' internal reflection on their academic performance as well as students' subjective comparative appraisal of their overall academic performance), rather than aiming only on 'downstream' indicators of academic performance, e.g., degree attainment or GPA that could overlook any adverse influences of smoking on academic performance and engagement among students who actually graduate.

\section{CONCLUSIONS}

The level of smoking among this Finnish sample is concerning, and the findings can inform interventions and policy. The general focus could be on global measures such as awareness about the adverse effects of smoking and risk perceptions. Specific focus could be on the modifiable independent predictors that were associated with more than one of the variables examined, e.g., PA, alcohol consumption and illicit drug use. Coordinated interventions to increase PA and highlight its importance could be stimulated at the university by motivation and providing resources, and prevention of the initiation and consumption of alcohol and illicit drug/s are also warranted. Likewise, educational efforts to raise students' health awareness generally could prove promising. In addition to the above, a range of interventions e.g. smoking cessation services should be implemented at university and could target the student groups at risk (e.g., older students, those feeling study burdens or that achieving good grades is not important, or those feeling depressive symptoms or other mental health issues). Universities would also benefit from providing students with more information about advantages and possibilities of smoking cessation including offers of treatment of nicotine dependence.

\section{Acknowledgements}

The authors thank Prof S. Suominen, and the students and faculties that participated in the research.

\section{Conflicts of Interests}

None declared

\section{Authors' Contributions}

W.E.A. - conceptualization; W.E.A. - methodology; A.S. - software; A.S. - formal analysis; W.E.A. - investigation; W.E.A. - writing, original draft preparation; W.E.A., A.S. - writing, review and editing; W.E.A. project administration. All authors have read and agreed to the published version of the manuscript. 


\section{REFERENCES}

1. Staten RR, Ridner SL. College students' perspective on smoking cessation: "If the message doesn't speak to me, I don't hear it". Issues Ment Health Nurs. 2006;28(1):101-15.

2. 2. El Ansari W, Labeeb S, Kotb S, Yousafzai MT, El-Houfey A, Stock C. Correlates of smoking, quit attempts and attitudes towards total smoking bans at university: findings from eleven faculties in Egypt. Asian Pac J Cancer Prev. 2012;13(6):2547-56.

3. Rigotti NA, Lee JE, Wechsler H. US college students' use of tobacco products: results of a national survey. JAMA. 2000;284(6):699-705.

4. Stock C, Larsen NM. The lifestyles of university students and their interest in campus health promotion. A cross-sectional study. Ugeskr Laeger. 2008;170(5):334-9. (In Danish.)

5. von Bothmer MI, Fridlund B. Gender differences in health habits and in motivation for a healthy lifestyle among Swedish university students. Nurs Health Sci. 2005;7(2):107-18.

6. Lund KE, Tefre EM, Amundsen A, Nordlund S. Cigarette smoking, use of snuff and other risk behaviour among students. Tidsskr Nor Laegeforen. 2008;128(16):1808-11. (In Norwegian.)

7. Provenzano S, Santangelo OE, Grigis D, Giordano D, Firenze A. Smoking behavior among nursing students: attitudes toward smoking cessation. J Prev Med Hyg. 2019;60(3):E203-10.

8. El Ansari W, Stock C. Factors associated with smoking, quit attempts and attitudes towards total smoking bans at university: a survey of seven universities in England, Wales and Northern Ireland. Asian Pac J Cancer Prev. 2012;13(2):705-14.

9. Seo DC, Macy JT, Torabi MR, Middlestadt SE. The effect of a smoke-free campus policy on college students' smoking behaviors and attitudes. Prev Med. 2011;53(4-5):347-52.

10. Allen B, Stuart GL. Decreased cigarette smoking but no change in use of electronic cigarettes following a university-wide smoking ban. Subst Abuse. 2019;13:1178221819874351. doi: 10.1177/1178221819874351.

11. Albers AB, Siegel M, Cheng DM, Biener L, Rigotti NA. Relation between local restaurant smoking regulations and attitudes towards the prevalence and social acceptability of smoking: a study of youths and adults who eat out predominantly at restaurants in their town. Tob Control. 2004;13(4):347-55.

12. Burns S, Bowser N, Smith J, Jancey J, Crawford G. An exploratory study of smokers' and stakeholders' expectations of the implementation of a smoke-free policy in a university setting. Health Promot J Austr. 2014;25(2):129-35

13. Knaappila N, Marttunen M, Fröjd S, Lindberg N, Kaltiala-Heino R. Socioeconomic trends in adolescent smoking in Finland from 2000 to 2015. J Adolesc Health. 2019;64(6):776-82

14. Banazadeh N, Sabahi A, Ziaadini H, Jalali-Khalilabadi A, Banazadeh $\mathrm{M}$. The relationship between extrinsic and intrinsic religious orientation with perceived stress and cigarette addiction among university students. Addict Health. 2019;11(2):73-80.

15. Bennasar-Veny M, Yañez AM, Pericas J, Ballester L, FernandezDominguez JC, Tauler P, et al. Cluster analysis of health-related lifestyles in university students. Int J Environ Res Public Health. 2020;7(5):1776. doi: 10.3390/ijerph17051776.

16. 16. Vorster A, Gerber AM, van der Merwe LJ, van Zyl S. Second and third year medical students' self-reported alcohol and substance use, smoking habits and academic performance at a South African medical school. Health SA. 2019;24:1041. doi: 10.4102/hsag.v24i0.1041.

17. Asghari F, Kurdmirza EO, Ahmadi L. The relationship between religious attitudes, locus of control and tendency to substance abuse in university students. Res Addict. 2013;7(25):103-12. [In Persian.]

18. Pennanen M, Haukkala A, de Vries H, Vartiainen E. Longitudinal study of relations between school achievement and smoking behavior among secondary school students in Finland: results of the ESFA study. Subst Use Misuse. 2011;46(5):569-79.

19. El Ansari W, Salam A, Suominen S. Is alcohol consumption associated with poor perceived academic performance? Survey of undergraduates in Finland. Int J Environ Res Public Health. 2020;17(4):1369. doi: 10.3390/ ijerph17041369.

20. El Ansari W, Salam A, Suominen S. Prevalence and socio-demographic, academic, health and lifestyle predictors of illicit drug/s use among university undergraduate students in Finland. Int J Environ Res Public Health. 2020;17(14):5094. doi: 10.3390/ijerph17145094.

21. Heikkinen R, Kivastik J, Kingisepp PH, Hirvonen L, Näyhä S. Smoking differences between university faculties in Tartu, Estonia, and
Oulu, Finland, after the disruption of communism. Soz Praventivmed. 2006;51(6):381-91.

22. Tobacco-free Finland 2030. Tobacco Act [Internet]. Helsinki: Tobaccofree Finland 2030 [cited 2020 Mar 20]. Available from: https://savutonsuomi.fi/en/towards-tobacco-free-finland/tobacco-act/.

23. WHO Framework Convention on Tobacco Control. FINLAND - Action plan to make the country smoke-free by 2040 . [Internet]. Geneva: WHO FCTC; 2014 [cited 2020 Mar 20]. Available from: https://www.who.int/ fctc/implementation/news/news Fin/en/.

24. 24. El Ansari W, Vallentin-Holbech L, Stock C. Predictors of illicit drug/s use among university students in Northern Ireland, Wales and England. Glob J Health Sci. 2014;7(4):18-29.

25. El Ansari W, Suominen S, Berg-Beckhoff G. Is healthier nutrition behaviour associated with better self-reported health and less health complaints? Evidence from Turku, Finland. Nutrients. 2015;7(10):8478-90.

26. El Ansari W, Sebena R, Stock C. Do importance of religious faith and healthy lifestyle modify the relationships between depressive symptoms and four indicators of alcohol consumption? A survey of students across seven universities in England, Wales, and Northern Ireland. Subst Use Misuse. 2014;49(3):211-20.

27. El Ansari W, Stock C, Phillips C, Mabhala A, Stoate M, Adetunji H, et al. Does the association between depressive symptomatology and physical activity depend on body image perception? A survey of students from seven universities in the UK. Int J Environ Res Public Health. 2011;8(2):281-99.

28. El Ansari W, Stock C. Is the health and wellbeing of university students associated with their academic performance? Cross sectional findings from the United Kingdom. Int J Environ Res Public Health. 2010;7(2):509-27.

29. El Ansari W, Samara A. Adherence to recommended dietary guidelines and the relationships with the importance of eating healthy in Egyptian university students. Int J Prev Med. 2018;9:73. doi: 10.4103/ijpvm. IJPVM 61914.

30. El Ansari W, Khalil KA, Ssewanyana D, Stock C. Behavioral risk factor clusters among university students at nine universities in Libya. AIMS Public Health. 2018;5(3):296-311.

31. El Ansari W, Berg-Beckhoff G. Nutritional correlates of perceived stress among university students in Egypt. Int J Environ Res Public Health. 2015;12(11):14164-76.

32. El Ansari W, Berg-Beckhoff G. Association of health status and health behaviors with weight satisfaction vs. body image concern: analysis of 5888 undergraduates in Egypt, Palestine, and Finland. Nutrients. 2019;11(12):2860. doi: 10.3390/nu11122860.

33. El Ansari W, Stock C. Explaining the gender difference in self-rated health among university students in Egypt. Women Health. 2016;56(7):731-44.

34. American College Health Association. American College Health Association National College Health Assessment (ACHA-NCHA): Spring 2006 Reference Group data report (abridged). J Am Coll Health. 2007;55(4):195-206.

35. Beck AT, Steer RA, Ball R, Ranieri W. Comparison of beck depression inventories - IA and II in psychiatric outpatients. J Pers Assess. 1996;67(3):588-97.

36. Schmitt M, Beckmann M, Dusi D, Maes J, Schiller A, Schonauer K. Validity of the simplified Beck Depression Inventory. Diagnostica. 2003;49(4):147-56. (In German.)

37. Cohen S, Kamarck T, Mermelstein R. A global measure of perceived stress. J Health Soc Behav. 1983;24(4):385-96.

38. Hurrelmann K, Kolip P. Survey on the health of school-age children. In: Presseinformationsdienst des SFB 227, No. 11. Bielefeld: University of Bielefeld; 1994. (In German.)

39. Seo DC, Nehl E, Agley J, Ma SM. Relations between physical activity and behavioral and perceptual correlates among midwestern college students. J Am Coll Health. 2007;56(2):187-97.

40. Haskell WL, Lee IM, Pate RR, Powell KE, Blair SN, Franklin BA, et al. Physical activity and public health: updated recommendation for adults from the American College of Sports Medicine and the American Heart Association. Circulation. 2007;116(9):1081-93.

41. Lee Y, Lee KS, Kim H. Predictors of abstinence from smoking: a retrospective study of male college students enrolled in a smoking cessation service. Int J Environ Res Public Health. 2019;16(18):3363. doi: 10.3390/ ijerph16183363.

42. Lam TS, Tse LA, Yu IT, Griffiths S. Prevalence of smoking and environmental tobacco smoke exposure, and attitudes and beliefs towards tobacco control among Hong Kong medical students. Public Health. 2009;123(1):42-6. 
43. Rodríguez-Muñoz PM, Carmona-Torres JM, Rodríguez-Borrego MA Influence of tobacco, alcohol consumption, eating habits and physical activity in nursing students. Rev Lat Am Enfermagem. 2020;28:e3230. doi: 10.1590/1518-8345.3198.3230.

44. ASH Finland. Smoking [Internet]. Helsinki: ASH Finland [cited 2020 Jan 8]. Available from: https://suomenash.fi/en/facts-about-smoking/ smoking/.

45. Solberg LI, Boyle RG, McCarty M, Asche SE, Thoele MJ. Young adult smokers: are they different? Am J Manag Care. 2007;13(11):626-32.

46. Bartington SE, Wootton R, Hawkins P, Farley A, Jones LL, Haroon S. Smoking behaviours and attitudes towards campus-wide tobacco control policies among staff and students: a cross- sectional survey at the University of Birmingham. BMC Public Health. 2020;20:252. doi: 10.1186/ s12889-020-8321-9.

47. Wilson LM, Avila Tang E, Chander G, Hutton HE, Odelola OA, Elf $\mathrm{JL}$, et al. Impact of tobacco control interventions on smoking initiation, cessation, and prevalence: a systematic review. J Environ Public Health. 2012;2012:961724. doi: 10.1155/2012/961724.

48. Latorre-Román PÁ, Gallego-Rodríguez M, Mejía-Meza JA, García-Pinillos F. Alcohol, and tobacco consumption and sports practice in Mexican and Spanish university students and the association between quality of life and health and sensation seeking. Gac Med Mex. 2015;151(2):197205. (In Spanish.)

49. Strine TW, Okoro CA, Chapman DP, Balluz LS, Ford ES, Ajani UA, et al. Health-related quality of life and health risk behaviors among smokers. Am J Prev Med. 2005;28(2):182-7.
50. Nduaguba SO, Ford KH, Rascati K. The role of physical activity in the association between smoking status and quality of life. Nicotine Tob Res. 2019;21(8):1065-71

51. Fujita Y, Maki K. Associations of smoking behavior with lifestyle and mental health among Japanese dental students. BMC Med Educ. 2018;18:264. doi: 10.1186/s12909-018-1365-1.

52. Yoo HH, Cha SW, Lee SY. Patterns of alcohol consumption and drinking motives among Korean medical students. Med Sci Monit. 2020;26:e921613. doi: 10.12659/MSM.921613.

53. Gazibara T, Milic M, Parlic M, Stevanovic J, Lazic D, Maric G, et al. Illict drug use and academia in North Kosovo: prevalence, patterns, predictors and health-related quality of life. PLoS One. 2018;13(7):e0199921. doi: 10.1371/journal.pone.0199921.

54. Schilling L, Zeeb H, Pischke C, Helmer S, Schmidt-Pokrzywniak A Reintjes R, et al. Licit and illicit substance use patterns among university students in Germany using cluster analysis. Subst Abuse Treat Prev Policy. 2017;12(1):44. doi: 10.1186/s13011-017-0128-z.

55. Tucktuck M, Ghandour R, Abu-Rmeileh NME. Waterpipe and cigarette tobacco smoking among Palestinian university students: a cross-sectional study. BMC Public Health. 2018;18:1. doi: 10.1186/s12889-017-4524-0.

Received October 10, 2020 Accepted in revised form January 11, 2021 